\title{
Adsorption of Chromium (VI) on Raw and Modified Carpathian Diatomite
}

\author{
Alicja Puszkarewicz ${ }^{1 *}$, Jadwiga Kaleta' \\ 1 Faculty of Civil and Environmental Engineering and Architecture, Rzeszow University of Technology, \\ ul. Poznańska 2, 35-084 Rzeszów, Poland \\ * Corresponding author's e-mail: apuszkar@prz.edu.pl
}

\begin{abstract}
The paper presents the research on the usability of natural Carpathian diatomite for removing chromate ions from water solutions. The concentration of chromium (VI) in test water was $\mathrm{C}_{0}=1 \mathrm{~g} / \mathrm{m}^{3}$. Both raw diatomite and the diatomite modified with iron compounds of granulation $0.5-1.0 \mathrm{~mm}$ were tested. The process kinetics, as well as the effect of water reaction and the diatomite type on chromium sorption were determined under static conditions (no through flow). For both diatomite types, the chromium adsorption proceeded most effectively at $\mathrm{pH} 4$. The effect of diatomite modification with iron compounds on the effectiveness of chromium (VI) adsorption was determined on the basis of Freundlich adsorption isotherm. Compared to raw diatomite, the modified adsorbent (diatomite$\mathrm{Fe}$ ) exhibited great sorption capacity for chromate ions from water. When applied under dynamic conditions $(\mathrm{v}=4 \mathrm{~m} / \mathrm{h})$, as filtration bed, it removed chromium compounds from water very effectively. It makes diatomite-Fe material a promising candidate for application in water treatment systems. The chromium concentration in the effluent oscillated within $\mathrm{C}_{\mathrm{k}}=0.001-0.002 \mathrm{mg} / \mathrm{dm}^{3}$, and the adsorption capacity of the bed, determined in the bed breakthrough point, reached $\mathrm{P}_{\mathrm{p}}=316.8 \mathrm{mg} / \mathrm{kg}$.
\end{abstract}

Keywords: adsorption, diatomite, removal of chromium(VI).

\section{INTRODUCTION}

Chromium is one of the heavy metals, the concentration of which in the environment is systematically growing. It is connected with progressing industrial development, in particular in metallurgical and chemical industries. Although there is no immediate risk of global contamination of natural environment with chromium compounds, their local supply/inputs to atmosphere, water and soils may cause excessive incorporation into the bio-geochemical circulation. the chromium (VI) compounds are considered most dangerous substances for humans and biocoenose as well. Excessive physiological concentrations of chromium (VI) become an allergic, or even carcinogenic, factor [Barabasz W. et.al. 1998]. Because of its toxic properties, chromium of this type is restricted in waters by the Regulation of the Minister of Environment (Journal of Laws,
2002, no. 204 item 1728) on requirements for surface waters used for population supply with potable water and their acceptable value should not exceed $0.02 \mathrm{mgCr}^{6+} / \mathrm{dm}^{3}$, whereas the content of chromium (VI) industrial effluents, discharged to receiving reservoir and sewage system depends on the branch of industry and is within the range of 0.05-0.5 mgCr ${ }^{6+} / \mathrm{dm}^{3}$ (Journal of Laws, 2006, no 136 item 964).

Sorption is one of the methods applied for removing chromium from water and effluents [Kim, S et al., 2016, Wazwaz A. et al., 2019., Yu, X et al., 2014.]. In a specific system (either through-flow or no flow type) this process lasts till the moment of establishing dynamic equilibrium of concentration of the adsorbate remaining in solution and on the internal surface of the adsorbent (equilibrium concentration). The time to reach the equilibrium is affected by the size of adsorbate particles and on its susceptibility to sorption process, as well as 
other factors. In a state of dynamic equilibrium there is a certain separation of adsorbate, i.e. between the solution and the adsorbent. This equilibrium is described using adsorption isotherms that reflect the relationship between the amount of substance adsorbed by/per unit mass of the adsorbent and the equilibrium concentration of the adsorbate at a constant temperature [Alutndogan H.S., 2005., Verma A., et.al. 2006].

Among adsorption isotherms, the equations proposed by Freundlich and Langmuir are particularly useful for mathematic description of adsorption from diluted aqueous solutions. Due to its simple structure, ease of mathematical solving and sufficient precision for describing of experimental results, the Freundlich adsorption isotherm is commonly applied, especially for natural water solutions [Guru M., et al., 2008, Krishna B. S. et al., 2000].

Adsorption on active carbon is the most popular sorption method for removing heavy metals (including chromium $\mathrm{Cr}^{6+}$ ) from water. The possibility of sorbent incineration (with alkali addition) and further processing of adsorbed chromium constitute an additional advantage of this method, while relatively high cost of production is a drawback [Mohan D., Pittman C.U., 2006].

Presently, much cheaper and easily available environment-friendly materials gained appreciation as sorbents [Chojnacka M., et al. 2017, Dubey P. S., 2007, Gupta V. K, et al.1999]. Among them, diatomite deserves mentioning, because its structure and physicochemical properties seem promising for obtaining good adsorptive capacity in respect to chromium [Guru M., 2008, Khraisheh M.A.M., 2004]. It has very wide economic application. The porous structure of diatom shells (of which diatomite is built) provides huge active surface, enables sorption of fluids and catalysts, thus making diatomite a perfect absorbent. It has proven to be good sorbent of oil compounds from water, carrier of various substances (e.g. chemical fertilizers, nitro-glycerin), as well as good material filtration to reduce or remove coloring and turbidity [Puszkarewicz A., 2004]. The diatomite surface, exhibiting negative charge in an aqueous medium may be modified chemically, thus raising its power and adsorption capacities in respect to removed compounds, e.g. $\mathrm{Cr}(\mathrm{VI})$, phenol or As (III) [Dantas T.N., et al. 2001, Karatepe N., et al. 2004, Knoerr R., et al. 2013, Krishna B. S. et al., 2000, Puszkarewicz A., 2010].

This paper presents the research on diatomite usability as an adsorbent for removing chromate ions from water, as well as determines the effect of diatomite modification with iron compounds on the adsorption effectiveness of chromium (VI).

\section{MATERIALS AND METHODS}

The tests were carried out on a model aqueous solution. It was prepared using tap water with the $\mathrm{pH}$ of 7.0-7.2 and adding compounds of chromium $\left(\mathrm{Cr}^{6+}\right)$ in the form of potassium dichromate $\mathrm{K}_{2} \mathrm{Cr}_{2} \mathrm{O}_{7}$. The initial concentration of chromium in water was $\mathrm{C}_{0}=1 \mathrm{mg} / \mathrm{dm}^{3}$.

\section{RESEARCH MATERIAL}

Granulated diatomite of grain size 0.5-1.0 mm, from strip mine in Jawornik Ruski, from the northern section of Leszczawka deposit (in the Podkarpackie province) was used as initial material [Diatomite products, 2004]. The physicochemical properties of diatomite are presented in Table 1.

The tests were carried out using two types of diatomite: diatomite dried at the temperature of $105^{\circ} \mathrm{C}$ (also called raw diatomite) and diatomite modified with iron compounds (called Fe- diatomite).

The diatomite modification consisted in impregnation of its surface with compounds of iron (III). It was a slightly changed version of the modification proposed by Thirunavukkarasu [Thirunavukkarasu O.S., et al. 2003].

Table 1. Physical and chemical properties of raw diatomite

\begin{tabular}{|l|c|l|c|}
\hline \multicolumn{1}{|c|}{ Parameter } & Contents & \multicolumn{1}{c|}{ Parameter } & \multicolumn{1}{c|}{ Contents } \\
\hline $\mathrm{SiO}_{3}$ & $68-73 \%$ & Specific density & $2.10-2.25 \mathrm{~g} / \mathrm{cm}^{3}$ \\
\hline $\mathrm{Al}_{2} \mathrm{O}_{3}$ & $9-12 \%$ & $\begin{array}{l}\text { Bulk density of products depending of } \\
\text { graining }\end{array}$ & $0.4-0.9 \mathrm{t} / \mathrm{m}^{3}$ \\
\hline $\mathrm{Fe}_{2} \mathrm{O}_{3}$ & $4-6 \%$ & Compression strength & $25-60 \mathrm{MPa}$ \\
\hline Porosity & $25-35 \%$ & Thermal conductivity & $0.25-0.30 \mathrm{kcal} / \mathrm{m} \cdot \mathrm{h} \cdot{ }^{\circ} \mathrm{C}$ \\
\hline Absorbability & $20-30 \%$ & Roasting losses $\left(900^{\circ} \mathrm{C}\right)$ & $7-10 \%$ \\
\hline
\end{tabular}


A $50 \%$ solution of $\mathrm{FeCl}_{3}$ and $\mathrm{NaOH}$ was used for this purpose. Diatomite, poured over with such solution, was left at room temperature for 24 hours and then dried at $105^{\circ} \mathrm{C}$. After drying, it was thoroughly washed with distilled water until clear washings were obtained and it was dried again. Therefore, the prepared diatomite was subject to two more cycles of modification according to the above-mentioned procedure.

\section{Batch experiments}

In order to define the optimum conditions for sorption process running and effect of diatomite modification on the sorption of chromate ions, the research work, realized in vessels with $0.5 \mathrm{dm}^{3}$ of adsorptive, was conducted in the following stages:

- determining of effect of solution $\mathrm{pH}$ on chromium sorption by diatomite ( $\mathrm{pH}$ was corrected within 2--9 $\mathrm{pH}$ range),

- determining the kinetics of sorption of chromate ions (for adsorption times between 10-300 minutes),

- executing of Freundlich adsorption isotherms for both tested diatomite materials (for $\mathrm{C}_{0}=1 \mathrm{mg} / \mathrm{dm}^{3}$ and diatomite doses varied from $1-100 \mathrm{mg} / \mathrm{dm}^{3}$ ),

- determining of adsorption capacity, $\mathrm{PA}_{\mathrm{s}}$, of adsorbents (on the basis of the formula (1)) for equilibrium concentration of adsorbate: $\mathrm{C}_{\mathrm{r}}=0.1 \mathrm{mg} / \mathrm{dm}^{3}$.

The adsorptive capacities were determined using Freundlich adsorption isotherm, which has the following exponential form:

$$
y / m=K \cdot C^{1 / n}
$$

where: $y$ - quantity of adsorbed substance [mg], $m$ - mass of the adsorbent $[\mathrm{g}]$, $C$ - equilibrium concentration $\left[\mathrm{mg} / \mathrm{dm}^{3}\right]$, $K, n$ - isotherm constants

In its exponential form, the Freundlich adsorption isotherm is poorly legible. Therefore, it was reformulated to linear form and the constants, $\mathrm{K}$ and $\mathrm{n}$, were determined on its basis.

After finding logarithm, the Freundlich adsorption isotherm assumes the following form (2):

$$
\log y / m=\log K+1 / n \log C
$$

\section{Continuous experiments}

The tests were conducted on laboratory filters with the diameters of $0.025 \mathrm{~m}$, filled with tested diatomite materials, with top-down gravitational flow and filtration rate of $4 \mathrm{~m} / \mathrm{h}$. Mass of diatomite filling in the filter was: $0.5 \mathrm{~kg}$.

Adsorption capacity, determined in the bed breakthrough point (rise of chromium concentration in the outflow), was calculated from the following relationship:

$$
P=V \cdot\left(C_{0}-C_{k}\right) / M
$$

where: $P$ - adsorption capacity of the bed $(\mathrm{mg} / \mathrm{kg})$,

$V$ - volume of treated water $\left(\mathrm{dm}^{3}\right)$,

$C_{0}, C_{\mathrm{k}}$ - initial and final concentration of chromium compounds $\left(\mathrm{mg} / \mathrm{dm}^{3}\right)$,

$M$ - bed mass (kg)

After each filtering of 5 liters of water, chromium compounds $\left(\mathrm{Cr}^{6+}\right)$ were checked in treated water. The amount of chromium (VI) present in the water was analyzed spectrophotometrically by measuring the absorbance of the purple complex of $\mathrm{Cr}(\mathrm{VI})$ with 1,5- diphenylcarbazide at $540 \mathrm{~nm}$.

\section{RESULTS AND DISCUSSION}

\section{Effect of modification}

In the research presented, the adsorption of chromium (VI) from water was carried out on raw and modified diatomite with iron compounds. In consequence, the diatomite-Fe surface became impregnated with iron oxides, $\mathrm{Fe}_{2} \mathrm{O}_{3}$ which have sorptive properties. Since modification of surfaces of solids changes the properties of surface-near layers in a controllable manner, the modification objective was to improve the sorption properties of the mineral.

Characteristic surfaces of row diatomite and diatomite-Fe were the value of BET method, with $\mathrm{N}_{2}$ adsorption, in liquid nitrogen with the temp. of $20^{\circ} \mathrm{C}$.

The surface for raw diatomite amount $\mathrm{S}_{\mathrm{R}}=20 \mathrm{~m}^{2} / \mathrm{g}$. After modification, the surface of diatomite-Fe increased to value $-\mathrm{S}_{\mathrm{M}}=27 \mathrm{~m}^{2} / \mathrm{g}$.

The structural change in diatomite surface is clearly visible in photographs (Fig. 1,2) taken with scanning microscope (at 5000 times magnification). Porous, reticular raw diatomite surface, with marked canals were completely covered with iron compounds in form of irregular narrow lamellas. In Figure 2, the circled location is where porous structure of raw diatomite shows up on the Fe-diatomite surface. 


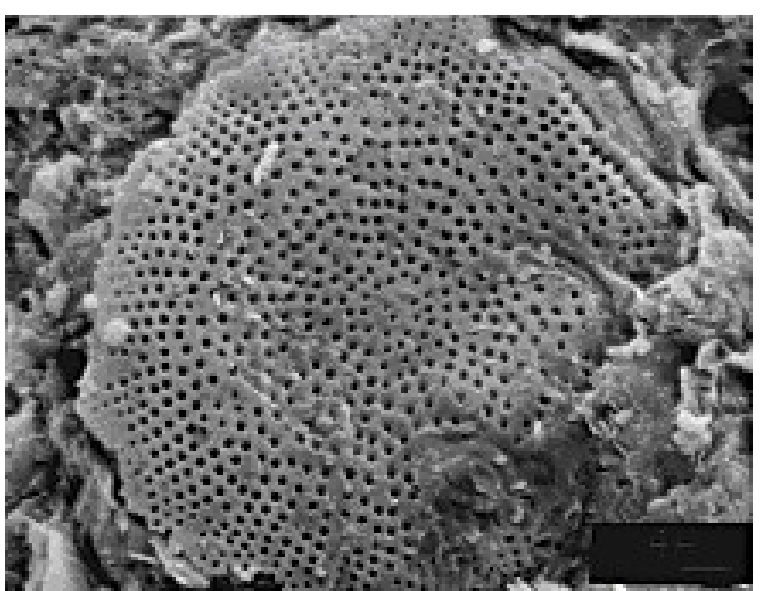

Fig. 1. Raw diatomite

\section{Batch experiments ( $\mathrm{pH}$, kinetics, isoterms)}

The tests conducted under static conditions to examine the effect of adsorbate $\mathrm{pH}$ and adsorption time (adsorption kinetics) on the removing of chromium (VI) had the objective to define the preconditions for the adsorption process conducted on both tested diatomite materials. Fig. 3 shows the effect of $\mathrm{pH}$ on the process of adsorption of chromium (VI).

The analysis of the obtained results shows that the adsorption of chromate anions $\left(\mathrm{Cr}_{2} \mathrm{O}_{7}^{2-}\right)$ proceeded best in acidic medium for both diatomite types. Anions are adsorbed much better on the surfaces with positive surface charge. Creating of positive charge in the diatomite-water interface may be caused by $\mathrm{H}^{+}$ion connecting to diatomite surface. The presence of electric charge in the solid-liquid system is an inherent feature, a result of the existing potential difference. For many solids, especially oxides, the $\mathrm{H}+$ and

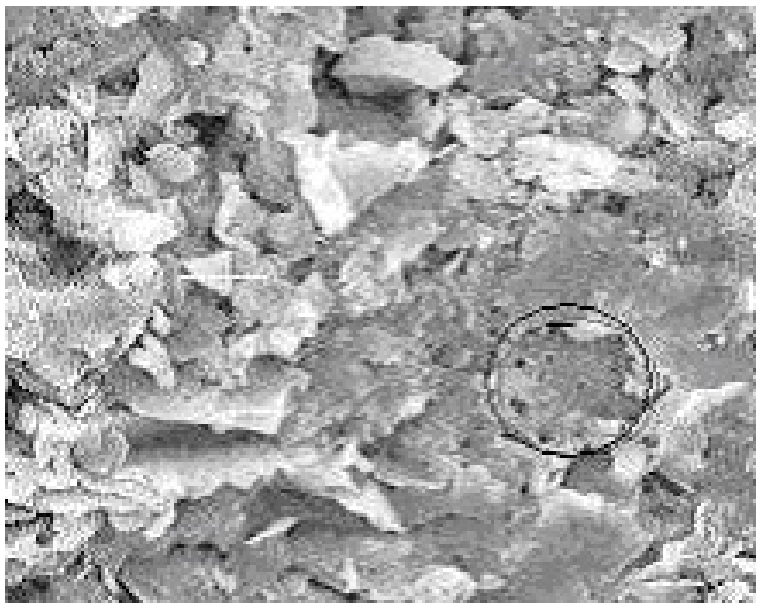

Fig. 2. Diatomite-Fe
$\mathrm{OH}-$ ions are potential generators. Thus, the surface potential may be altered by changing $\mathrm{pH}$ of the solution in which a given solid body is located. Therefore, depending on $\mathrm{pH}$ of the solution, in which the adsorbent is located, its surface will assume either positive or negative electric charge [Janusz W. 2000].

Most probably, the removing of chromium in anion form in acidic medium took place in two stages [Janusz W., et al. 2002]:

$$
\begin{aligned}
& \mathrm{MOH}+H^{+}=\mathrm{MOH}_{2}^{+} \\
& \mathrm{MOH}_{2}^{+}+A^{-}=\mathrm{MOH}_{2}^{+} A^{-}
\end{aligned}
$$

where: $\mathrm{M}$ - metal, e.g.: Fe,

$$
\mathrm{A}^{-}-\text {anion, e.g. } \mathrm{Cr}_{2} \mathrm{O}_{7}^{2-}
$$

The reductions achieved in the $\mathrm{pH}$ range of 2 to 4 were clearly the best. It appears that at such $\mathrm{pH}$ chromate ions (anions $\mathrm{Cr}_{2} \mathrm{O}_{7}^{2-}$ ) are adsorbed best on diatomite surface [Kim, S et al., 2016]. The alkali medium is not favorable for removing chromium (VI) and, moreover at $\mathrm{pH}$ higher than 8, there was a slight coloring of tested sample to brown color. Another research confirms that it may be the cause diatomite dissolving in alkali media [Verma A.,et.al. 2006]. Because of the comparable chromium reductions in the $\mathrm{pH}$ range of 2 to $4, \mathrm{pH}$ of 4 were assumed as optimum for the determination of adsorption isotherms.

Adsorption kinetics depends on the type of adsorbent, methods of its modification and the type of removed compound, the time period for attaining the state of adsorption equilibrium is within the range 30-120 minutes [Khraisheh M.A.M., 2004, Krishna B. S., 2000]. The test results indicate that adsorption time had a significant effect on the effectiveness of removing chromium (VI). For raw diatomite the maximum reduction of chromate ions took place after 120 minutes. The rate of chromium removal on Fe-diatomite was higher and the adsorption equilibrium was achieved after 60 min. (Fig. 4). Then, stabilization ensued and, contact times of $2 \mathrm{~h}$ and $1 \mathrm{~h}$ were assumed for further research (isotherm determination).

\section{Freundlich adsorption isotherms}

The adsorption process was characterized on the basis of Freundlich adsorption isotherms determined at $20^{\circ} \mathrm{C}$ and $\mathrm{pH}=4$, for both adsorbents.

The course of adsorption process is presented in Fig. 5. 


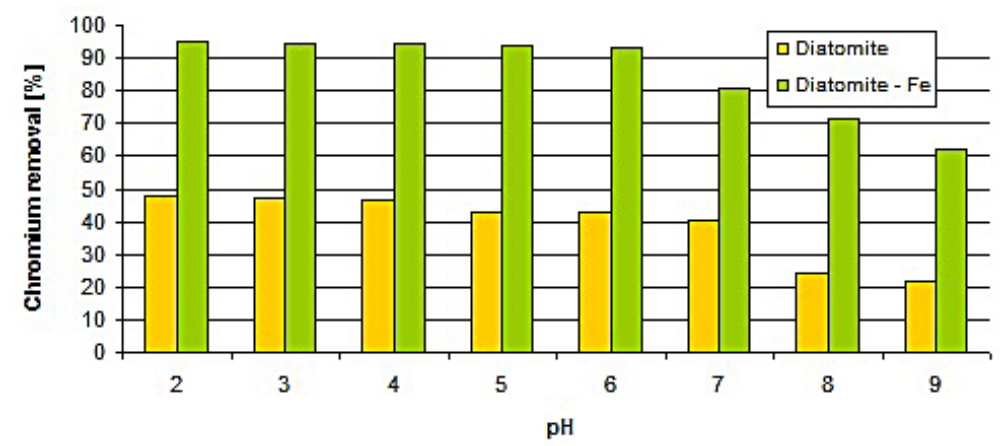

Fig. 3. Effect of $\mathrm{pH}$ on the process of adsorption of chromium (VI), $\mathrm{C}_{0}=1 \mathrm{mg} / \mathrm{dm}^{3}$

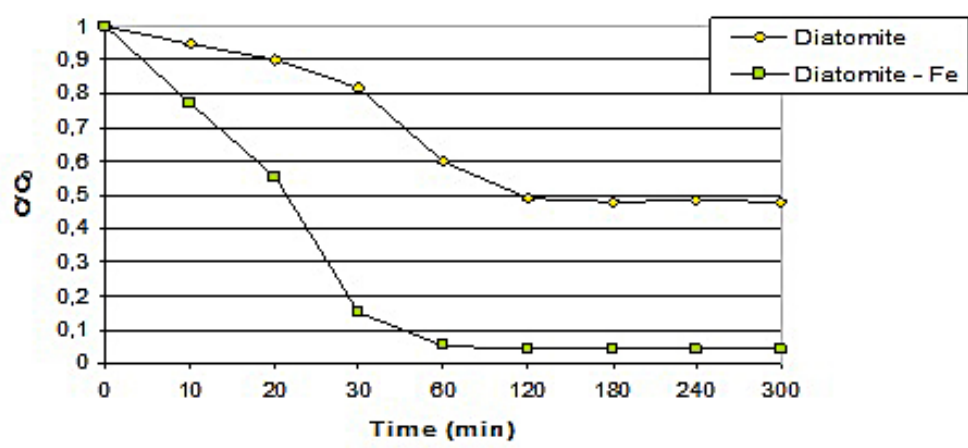

Fig. 4. Adsorption kinetics of chromium (VI) onto diatomite

The Freundlich adsorption isotherm in linear model for row diatomite took the form of: $y=1.973 x-0.911$, In turn, the Freundlich adsorption isotherm for diatomite-Fe assumed the form of: $y=0.6899 x+0.7848$.

Values of constants, $\mathrm{K}$ and $\mathrm{n}$ were following:

- for row diatomite: $\mathrm{K}=0.12, \mathrm{n}=0.51$,

- for diatomite-Fe: $\mathrm{K}=6.10, \mathrm{n}=1.45$.

The analysis of isotherms in linear form leads to the conclusion that the adjustment of Freundlich mathematical model to experimental results is very good, as evidenced by high correlation coefficients, R, of both adsorbents. For Fe- diatomite, this coefficient exceeded the value of $0.99(\mathrm{~K}=0.9910)$. For row diatomite the value of $\mathrm{K}=0.9308$.

The comparison of values of coefficients, $\mathrm{K}$ and $\mathrm{n}$, substantiates the statement that they were much higher for modified diatomite and comparable to values for adsorption of chromium compounds on other tested adsorbents [Gupta V. K, 1999, Guru M., 2008]. The calculated adsorptive capacity for equilibrium concentration, $\mathrm{C}_{\mathrm{r}}=0.1$ $\mathrm{mg} / \mathrm{dm}^{3}$ when using diatomite-Fe was $\mathrm{P}_{\mathrm{A}}=1.25$ $\mathrm{mg} / \mathrm{g}$ and it was several hundred times higher than the adsorptive capacity achieved for raw diatomite $\left(\mathrm{P}_{\mathrm{Ar}}=0.0004 \mathrm{mg} / \mathrm{g}\right)$. It is the evidence of much better adsorptive properties of diatomite modified with $\mathrm{Fe}$, in respect to chromate ions. When we compare this value with the adsorptive capacities for other adsorbents, it falls within the range obtained for some active carbons and other waste materials. For the majority of tested materials, the adsorptive capacities fall within the range of 0.1-250 mg/g [Mohan D., Pittman C.U., 2006].

Considering the fact that adsorption is quite often conducted under dynamic conditions, the research was continued with the compounds of chromium (VI) being removed in filtration process.

\section{Continuous experiments}

Filtration process was realized with constant rate, $v=4 \mathrm{~m} / \mathrm{h}$, with contact time $\mathrm{t}_{\mathrm{k}}=5 \mathrm{~min}$. The course of filtration with the use diatomite and Fe-diatomite beds is presented in Figure 6.

While analyzing the filtration process on diatomite bed, it is easy to observe that filtration lasted for very short times. The bed became completely exhausted after passing approx. 120 liters of tested water. The lowest concentration of chromium (VI) achieved in the outflow was merely $\mathrm{C}_{\mathrm{k}}=0.42 \mathrm{mg} / \mathrm{dm}^{3}$. For this diatomite, the adsorptive capacity was not calculated in its 


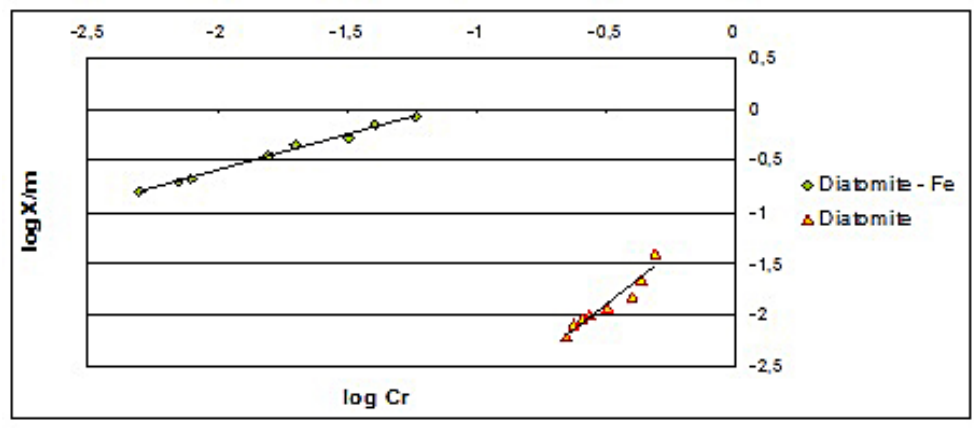

Fig. 5. Adsorption isotherms of chromium (VI) onto diatomite

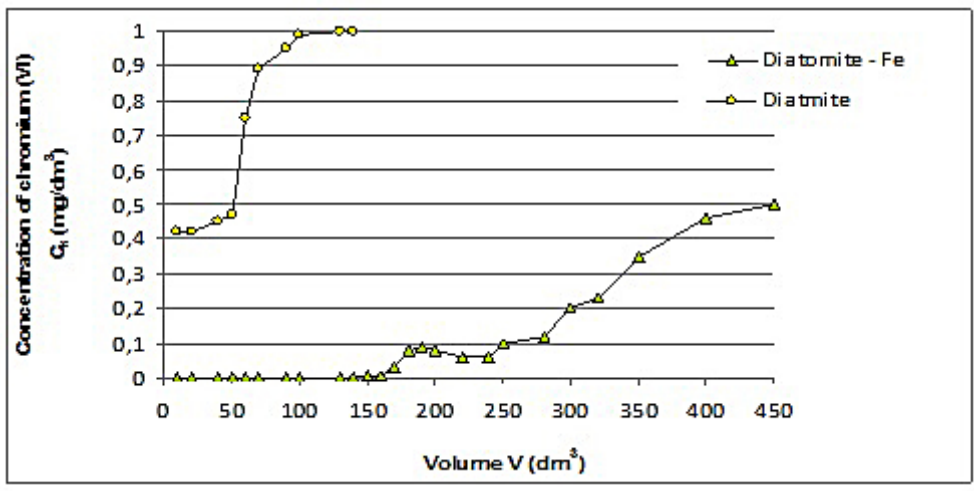

Fig. 6. Removal of chromium (VI) in filtration process

breakthrough point. Instead, the total adsorptive capacity of the bed was estimated in the point of exhaustion. It was approximately $\mathrm{P}_{\mathrm{c}}=56 \mathrm{mg} / \mathrm{kg}$. The filtration process with Fe-diatomite as adsorptive bed proceeded quite differently. Right after the filtration start the concentration of chromium (VI) in the outflow oscillated within the range of $\mathrm{C}_{\mathrm{k}}=0.000-0.002 \mathrm{mg} / \mathrm{dm}^{3}$. The adsorbate concentration in the outflow began to increase only after filtering approx. 160 liters of tested water. This moment of filtration was assumed as the breakthrough point $\left(\mathrm{V}=160 \mathrm{dm}^{3}, \mathrm{C}_{\mathrm{k}}=0.003 \mathrm{mg} / \mathrm{dm}^{3}\right)$ and the filtration capacity, $\mathrm{P}_{\mathrm{p}}$, was calculated for these parameters. It was much higher than in case of raw diatomite, i.e. $\mathrm{P}_{\mathrm{p}}=316 \mathrm{mg} / \mathrm{kg}$.

\section{CONCLUSIONS}

The process of sorption conducted on Carpathian diatomite materials showed that modified diatomite was useful for removing chromate irons (VI) from water. Modification of diatomite surfaces with iron compounds contributed significantly to raising the adsorptive properties of that mineral for sorption of chromate ions $\mathrm{Cr}_{2} \mathrm{O}_{7}^{2-}$ from water. Owing to the coating of diatomite surface of iron oxides, the adsorption surface increased at $35 \%$. Diatomite surface was able to resume positive surface charge and adsorbent was instrumental in sorption on its surface molecule of chromium(V) with negative charge.

The degree of reduction of chromium (VI) was significantly influenced by $\mathrm{pH}$ of the solution, which enabled obtaining positive charge of Fe-diatomite surface. The $\mathrm{pH}$ level between 2 and 4 proved most favorable for maximum reduction of chromium (VI). The optimum time period needed for reaching adsorption equilibrium for Fe-diatomite was 60 minutes.

The adsorption equilibrium was analyzed on the basis of Freundlich model, which fitted very well to the experimental conditions in respect to Fe-diatomite and the obtained $\mathrm{K}$ and $\mathrm{n}$ constants were comparable to many other adsorbents [Knoerr R., et al. 2013].

Fe-diatomite of granulation 0.5-1.0 mm, applied as adsorptive bed very effectively (practically completely) removed chromium (VI) from water. Possibly, when the research is continued, the adsorption capacity, $\mathrm{P}_{\mathrm{p}}=316 \mathrm{mg} / \mathrm{kg}$, obtained in the breakthrough point, may be increased further by optimizing the hydraulic parameters of filtration (e.g. by extending the retention time or 
changing the granulation). The unquestionable advantage of Carpathian diatomite as adsorbent, despite its modest adsorption capacity in respect to chromium(VI), is its common occurrence and low cost.

\section{REFERENCES}

1. Alutndogan H.S., 2005. Cr(VI) removal from aqueous solution by iron (III) hyroxide-loaded sugar beet pulp, Process Biochemistry, 40 (3-4), 1443-1452.

2. Barabasz W., Chmiel M.J., Galus A., Pasmionka I., 1998. Ecotoxicology of chromium, Ecological Chemistry and Engineering5(8-9), 665-669.

3. Chojnacka M., Sobolewska P., Petrus R., Warchoł J., 2017. Sorpcja jonów $\mathrm{Cr}(\mathrm{VI})$ na powierzchniowo modyfikowanych zeolitach naturalnych. Przemysł Chemiczny 96(2), 332-337.

4. Dantas T.N., Dantas Neto A. A., De A. Moura M. C. P. , 2001. Removal of chromium from aqueous by diatomite treated with microemulsion, Water Res. 35(9), 2219-2224.

5. Diatomite products, 2004. Specialized Mining Company „Górtech” Sp.z o.o.

6. Dubey P. S., 2007. Adsorption of chromium (VI) on low cost adsorbents derived from agricultural waste material: A comparative study, Journal of Hazardous Materials 145, 465-470.

7. Gupta V. K, Mohan D. Kharma S., Park K.T., 1999. Removal of chromium VI from electroplating industry wastewaterusing bagasse fly ash-a sugar industry waste material, The Environmentalist 19, 129-136.

8. Guru M., Venedik D., Murathan A., 2008. Removal of trivalent chromium from water using low cost natural diatomite, Journal of Hazardous Materials, $160,318-323$.

9. Janusz W. 2000. The electrical double layer parameters for the group 4 metal oxide/electrolyte system, Adsorpt. Sci. Technol., 18(2), 117-134.

10. Janusz W., Skwarek E., Gałgan A., 2002. Electrical double layer at zirconium silicate/electrolyte solution interface, Pol. J. Chem., 76(5), 745-754.

11. Karatepe N., Erdogan N., Ersoy-Mericboyu A., Kucukbayrak S., 2004. Preparation of diatomite/ $\mathrm{Ca}(\mathrm{OH}) 2$ sorbents and modelling their sulpha- tion reaction, Chemical Engineering Science 59, 3883-3889.

12. Khraisheh M.A.M., Al-Degs Y. S., Mcminn W. A.M., 2004. Remediation of wastewater containing heavy metals using raw and modified diatomite, Chemical Engineering Journal 99, 177-184.

13. Kim, S et al., 2016. Simultaneous removal of chromium(VI) and Reactive Black 5 using zeolite supported nano-scale zero-valent iron composite, Environmental Earth Sciences, 75, p. 447.

14. Knoerr R., Brendle J., Lebeau B., Demais H., 2013. Preparation of ferric oxide modified diatomite and its application in the remediation of As(III) species from solution, Microporous and Mesoporous Materials, 169, 185-191.

15. Krishna B. S. Murty D. S., R, Prakash B. S. J., 2000. Thermodynamics of Chromium(VI) Anionic Species Sorption onto Surfactant-Modified Montmorillonite Clay, Journal of Colloid and Interface Science, 229, 230-236.

16. Mohan D., Pittman C.U., 2006. Activated Carbons and Low-Cost Adsorbents for Remediation of Triand Hexavalent Chromium from Water: A Review" Journal of Hazardous Materials, B137, 762 - 811.

17. Puszkarewicz A., 2004. Diatomites in environmental protection and economy, Scientific notebooks of the Rzeszów University of Technology, Civil and Environmental Engineering, 38, 109-118.

18. Puszkarewicz A., 2010. Analysis of phenol adsorption on raw and modified Carpathian diatomites, Chemistry -Didactics-Ecology-Metrology, 15 (2), 189-193.

19. Thirunavukkarasu O.S., Viraraghavan T., Subramanian K.S., 2003. Arsenic removal from drinking water using iron-coated sand, Water, Air and Soil Pollution, 142, 95-111.

20. Wazwaz A., Al-Salaymeh A., Khan M., S., 2019. Removing Heavy Metals Through Different Types of Soils and Marble Powder Found in Oman, J. Ecol. Eng.; 20(4), 136-142.

21. Verma A., Chakraborty S., Basu J.K., 2006. Adsorption study of hexavalent chromium using tamarind hull-based adsorbents, Separation and Purification Technology, 50, 336-341.

22. Yu, X et al., 2014. Kinetics for adsorptive removal of chromium(VI) from aqueous solutions by ferri hydroxide/oxohydroxides, Ecotoxicology 23, 734-741. 